\title{
PERANCANGAN SISTEM MONITORING DAYA UNTUK INVERTER SATU FASA GUNA PENGUKURAN DAYA TERALIR SECARA REALTIME
}

\author{
Muhammad Iqbal $^{*}$, Iwan Setiawan, Agung Nugroho \\ Departemen Teknik Elektro, Universitas Diponegoro \\ J1. Prof. Sudharto, SH, Kampus UNDIP Tembalang, Semarang 50275, Indonesia \\ ${ }^{*}$ Email: iqbal.muhammad@student.undip.ac.id
}

\begin{abstract}
Abstrak
Penggunaan energi listrik secara global meningkat dari tahun ke tahun dan efek emisi gas rumah kacapun masih dirasakan akibat pembakaran bahan bakar fosil. Hal tersebut mendorong peningkatan teknologi terhadap instalasi dengan sumber energi terbarukan berupa pembangkit listrik photovoltaic (PV) yang mempunyai potensi terbesar di Indonesia. Namun, sistem pada PV masih berupa DC sehingga diperlukan inverter untuk merubah sistem menjadi AC. Namun, ketika inverter menyuplai beban daya ada kemungkinan melebihi spesifikasinya. Oleh karena itu, penelitian ini merancang sistem monitoring daya secara realtime dan akurat untuk memastikan kualitas penyaluran daya sudah optimal dan sesuai spesifikasi. Metode yang diterapkan pada penelitian ini adalah metode Orthogonal Signal Generator (OSG) yang diproses oleh STM32F103C8T6. Metode tersebut menggunakan delay $1 / 4$ periode untuk mendapatkan nilai daya keluaran. Hasil pengujian diperoleh error daya aktif $1 \%$ pada beban 9,6 ohm dan 1,64\% pada Beban 47,5 Ohm, sedangkan pada daya reaktif didapat selisih 0,83 VAR pada beban 9,6 Ohm dan 0,89 VAR pada beban 47,5 Ohm. Berdasarkan buku PLN dikategorikan dalam alat kerja.
\end{abstract}

Kata kunci : OSG, STM32F103C8T6, grid voltage, daya aktif, daya reaktif

\begin{abstract}
The use of electrical energy globally increases every years and green house's effects are still felt due to fossil fuels. This encourages technological improvements to installations with renewable energy sources in the form of photovoltaic (PV) power plants that have the greatest potential in Indonesia. However, the system in PV is still in the form of DC so that an inverter is needed to change the system to AC. However, when the inverter supplies a power load there is a possibility of exceeding the specifications. Therefore, this Research designs a real-time and accurate power monitoring system to ensure the quality of power distribution is optimal and according to specifications. The method applied in this Research is the Orthogonal Signal Generator (OSG) method which is processed by STM32F103C8T6. This method uses a delay $1 / 4$ period to get the output power value. The test results obtained $1 \%$ active power error at $9.6 \mathrm{ohm}$ load and $1.64 \%$ at $47.5 \mathrm{Ohm}$ Load, while at reactive power obtained difference of 0.83 VAR at load 9.6 Ohm and 0.89 VAR at load 47,5 Ohm. Based on the book PLN is categorized in the work tool.
\end{abstract}

Keywords: OSG, STM32F103C8T6, grid voltage, active power, reactive power

\section{Pendahuluan}

Penggunaan konsumsi energi listrik secara global meningkat dari $13.934 \mathrm{TWh}$ pada tahun 2001 menjadi 24.673 TWh pada tahun 2025 yang mana mengacu pada Administrasi dan Informasi Energi, US[1]. Hal ini menjadikan pembangkit listrik konvensional dengan bahan bakar fosil tidak lagi memenuhi dalam perencanaan strategi energi nasional yang berkelanjutan. Efek emisi gas rumah kaca pun masih dirasakan akibat pembakaran bahan bakar fosil seperti batu bara, minyak bumi, gas alam dan lainnya. Kedua Hal tersebut mendorong untuk peningkatan teknologi terhadap instalasi dengan sumber energi terbarukan, seperti tenaga angin, tenaga surya matahari, tenaga air, tenaga biomassa, tenaga panas bumi, tenaga air laut, dan lainnya terhadap grid[1]. Diantara sumber energi terbarukan utama, pembangkit listrik tenaga surya (PV) mempunyai potensi terbesar di Indonesia yaitu 207.998 MW, kemudian diikuti tenaga air, angin, bioenergi, panas bumi, mini \& mikro hidro, dan gelombang laut. Sehingga sistem tenaga PV merupakan pilihan yang tepat dalam memaksimalkan penggunaan energi terbarukan di Indonesia.

Akan tetapi, output dari sistem PV ini masih berupa tegangan DC sehingga perlu diubah menjadi sistem AC agar dapat menyuplai peralatan elektronik rumah tangga. Oleh sebab itu, diperlukan adanya perangkat yang dapat mengubah dari sistem DC menjadi sistem AC. Inverter merupakan perangkat yang paling umum digunakan 
sebagai konverter untuk mengubah tegangan DC ke dalam tegangan AC[2]. Salah satu aplikasi inverter yang paling sering dijumpai adalah pada sistem photovoltaic yang tersambung dengan grid. Sistem grid ini tersambung dengan sistem PLN sehingga tegangan yang dikeluarkan inverter tersinkronisasi atau sesuai dengan ketentuan dari PLN[3]. Untuk mengetahui besar daya yang tersalurkan antara inverter dengan grid yang dimisalkan dengan suatu beban, maka dibutuhkan suatu alat untuk monitoring daya agar dapat mengetahui nilai besar arus dan tegangan agar sesuai dengan spesifikasi pada inverter.

Penelitian ini merancang sistem monitoring daya dengan metode Orthogonal Signal Generator (OSG) yang akan diimplementasikan pada inverter satu fasa tipe Full Bridge. Metode OSG digunakan untuk melakukan pergeseran fase $90^{\circ}$ terhadap nilai awal dari arus dan tegangan[4]. Setelah digeser, maka selanjutnya dilakukan transformasi pq untuk mengubah nilai tegangan dan arus tersebut menjadi nilai daya[5]. Sistem monitoring untuk inverter satu fasa akan dirancang terlebih dahulu dengan menggunakan Simulink Matlab untuk memastikan bagaimana sistem monitoring dan pengukuran yang akan dirancang. Sistem monitoring dikontrol oleh mikrokontroler STM32F103C8T6. Sinyal tegangan diproses dari rangkaian pengkondisi sinyal dengan spesifikasi tegangan $60 \mathrm{~V}$ sistem satu fasa. Sinyal arus diproses dari sensor arus DT Sense With OpAmp dengan spesifikasi arus 5 A dan nilai sensitivitas $185 \mathrm{~mA} / \mathrm{V}$. Dari sistem ini, diharapkan sistem monitoring daya ini dapat menghitung daya lebih cepat dan akurat, serta mengetahui besar daya terserap oleh beban sehingga dapat mengatur sistem pada inverter agar tetap sesuai dengan spesifikasi.

\section{Metode}

\subsection{Perancangan Perangkat Keras}

Perancangan sistem monitoring inverter satu fasa terdiri dari blok suplai daya listrik, blok rangkaian kontrol, blok sensor arus DT Sense With Op Amp, blok pengkondisi sinyal, blok penampil LCD, dan blok beban.

Blok rangkaian daya berupa rangkaian rectifier 1 fasa. Blok rangkaian kontrol terdiri dari mikrokontroler STM32F103C8T6. Diagram blok perangkat keras yang dirancang pada penelitian ini ditunjukkan pada Gambar 1.

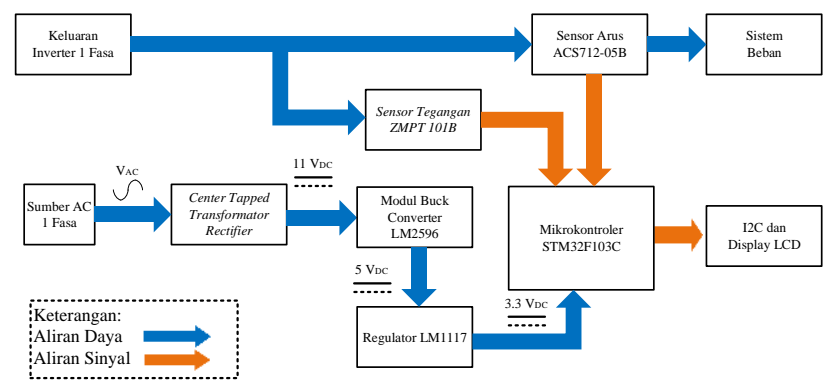

Gambar 1. Diagram Blok Perancangan Perangkat Keras
Spesifikasi sistem monitoring daya inverter satu fasa tipe full bridge berdasarkan Gambar 1 yang dirancang pada penelitian ini dijelaskan sebagai berikut.

1. Sumber tegangan AC 1 fasa digunakan untuk mensuplai rangkaian daya dan rangkaian mikrokontroler.

2. Suplai tegangan DC untuk rangkaian daya rangkaian mikrokontroler diperoleh dari hasil penyearahan tegangan $\mathrm{AC}$ menggunakan center tapped full wave rectifier 1 fasa.

3. Suplai tegangan 8 VDC masuk ke modul Buck Converter XL4015 untuk menurunkan besaran tegangan menjadi 5 Volt.

4. Suplai tegangan 5 VDC masuk ke Regulator LM1117 untuk menurunkan besaran tegangan menjadi 3.3 VDC yang menjadi input mikrokontroler STM32F103C8T6.

5. Sensor arus DT Sense With OpAmp digunakan untuk mengukur arus keluaran inverter dan mengirim informasi berupa tegangan kepada mikrokontroler STM32F103C8T6.

6. Rangkaian pengkondisi sinyal digunakan untuk mengukur tegangan keluaran inverter dan mengirim informasi berupa tegangan kepada mikrokontroler STM32F103C8T6.

7. Mikrokontroler 32-Bit STM32F103C8T6 digunakan untuk membaca sinyal dari sensor arus DT Sense With OpAmp dan rangkaian pengkondisi sinyal, serta memproses dari pembacaan sensor menjadi output berupa daya aktif dan reaktif.

8. Hasil pembacaan tegangan, arus, daya aktif, dan daya reaktif dari mikrokontroler STM32F103C8T6 ditampilkan melalui LCD dengan modul I2C (Inter Integrated Circuit) untuk mempermudah mengoneksikan LCD ke mikrokontroler dengan mencakup semua pin LCD pada modul I2C.

9. Blok beban terdiri dari beban yang terhubung dengan keluaran inverter satu fasa. Beban yang digunakan dalam perancangan penelitian ini adalah berupa beban resistif.

\subsubsection{Perancangan Pengkondisi Sinyal}

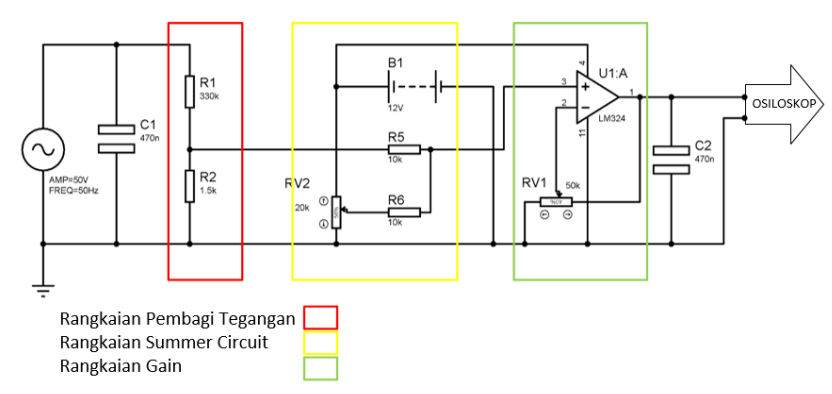

Gambar 2. Skema Rangkaian Pengkondisi Sinyal

Berdasarkan Gambar 2, sumber tegangan 1 fase $50 \mathrm{~V} / 50 \mathrm{~Hz}$ dari inverter masuk ke blok rangkaian pembagi 
tegangan untuk diturunkan tegangannya, sehingga saat sinyal tegangan diangkat ke atas garis nol, magnitudenya $\leq 3,3 \mathrm{~V}$ pada blok summer circuit, untuk keperluan mengatur posisi gelombang digunakan potensiometer $20 \mathrm{~K}$ $\Omega$ sebagai pengatur tegangan DC yang dihasilkan, untuk nantinya mengangkat gelombang keluaran dari blok rangkaian pembagi tegangan. Yang terakhir yaitu mengatur besar magnitude gelombang menggunakan potensiometer $50 \mathrm{~K} \Omega$ yang ada pada blok gain circuit, yang terdiri dari sebuah IC LM324N yang merupakan IC Op-Amp dan sebuah potensiometer $50 \mathrm{~K} \Omega$ sebagai pengatur besar kecilnya magnitude gelombang. Perlu diketahui bahwa tegangan input dari inverter bisa saja berubah-ubah sehingga diperlukan rangkaian sensor yang dinamis untuk bisa selalu menghasilkan sinyal keluaran sensor sebaik mungkin.

Idealnya, tegangan $50 \mathrm{~V}$ dari inverter masuk ke pembagi tegangan untuk diturunkan tegangannya sehingga ketika tegangan diangkat di atas nol tidak melebihi $3,3 \mathrm{~V}$. $O p$ Amp LM324N akan menguatkan tegangan keluaran trafo yang kombinasikan dengan potensiometer, kita dapat mengatur gelombang tegangan keluaran sensor sesuai keinginan kita antara $0-3,3 \mathrm{~V}$ sinus. Kita atur tegangan minimum $0.4 \mathrm{~V}$ dan tegangan maksimum $2.88 \mathrm{~V}$. Kita atur tegangan minimum $0.4 \mathrm{~V}$ dan tegangan maksimum $2.88 \mathrm{~V}$. Pemilihan ini memberikan jarak $0.4 \mathrm{~V}$ dari batas 3,3 V untuk mencegah tegangan naik hingga melebihi 3,6 $\mathrm{V}$, karena jika melebihi $3,6 \mathrm{~V}$ akan mengganggu pemrosesan data pada dsPIC30F401.

\subsubsection{Sensor Arus ACS-712 5B}

Pada perancangan penelitian ini, potensiometer offset dari tegangan output sensor diatur sedemikian rupa sehingga saat arus yang mengalir melewati sensor adalah sebesar 0 A, tegangan output sensor adalah sebesar $2,5 \mathrm{~V}$, hal ini berarti bahwa titik tengah dari tegangan output sensor berada pada nilai tegangan $2,5 \mathrm{~V}$ tersebut. Lalu potensiometer gain diatur hingga nilai sensitivitas sensor berubah menjadi $0,5 \mathrm{~V} / \mathrm{A}$, sehingga nilai tegangan keluaran maksimal dari sensor saat arus yang terbaca sebesar 5 A sesuai dengan Persamaan 1 berikut.

$\mathrm{V}$ out $=2,5+0,5 \cdot \mathrm{i}$

V_out $=2,5+0,5 \cdot 5$

V_out $=5 \mathrm{~V}$

Tegangan keluaran sensor diatur menjadi maksimal $5 \mathrm{~V}$ untuk memudahkan pembacaan oleh modul analog-todigital converter yang memiliki tegangan referensi sebesar 5 V. Realisasi perangkat keras sensor arus ACS712-05B yang digunakan dalam perancangan penelitian ini ditunjukkan pada Gambar 3 berikut.

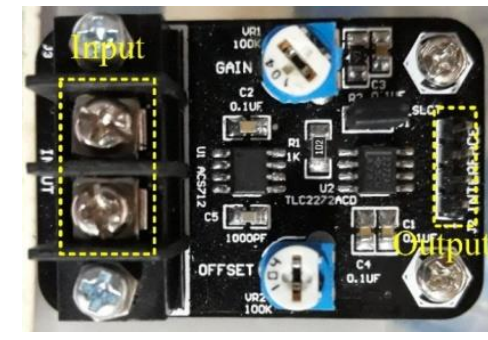

Gambar 3. Sensor ACS-712 05B

\subsubsection{Alokasi Pin Mikrokontroler}

Mikrokontroler yang digunakan dalam penelitian ini adalah mikrokontroler STM32F103C8T6 yang berfungsi sebagai pemroses program OSG. Pada mikrokotroler STM32F103C8T6 terdapat 7 pin utama yang digunakan pada penelitian ini. Terdapat pin PA0 yang digunakan sebagai input ADC dari rangkaian pengkondisi sinyal, pin PA2 sebagai input ADC dari sensor arus DT Sense With OpAmp. Pin PB6 dan PB7 digunakan sebagai penghubung ke modul I2C dan LCD. Pin 5 Volt digunakan sebagai suplai LCD, pin 3.3 Volt sebagai suplai sensor, dan GND sebagai ground sensor, dan I2C. Berikut merupakan skema alokasi masukan dan keluaran pin mikrokontroler STM32F103C8T6. Untuk lebih jelasnya dapat dilihat pada Gambar 4

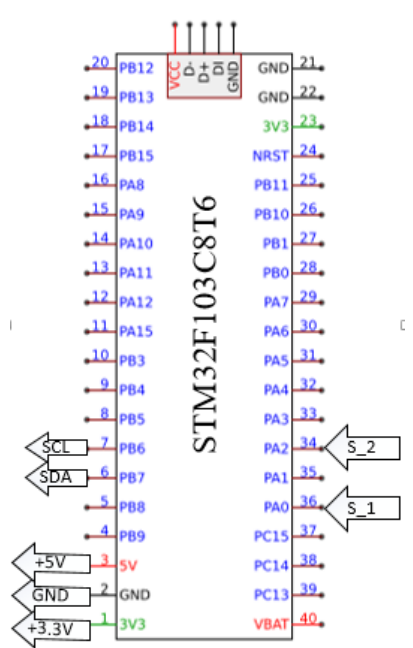

Gambar 4. Alokasi input-output mikrokontroler

\subsection{Perancangan Simulasi}

Pada penelitian ini, sistem monitoring yang digunakan menggunakan metode Orthogonal Signal Generator (OSG) sebagai referensi untuk menghitung daya aktif dan reaktif output dari inverter 1 fasa. Metode yang digunakan ini bekerja dengan cara menunda waktu sebesar seperempat periode sehingga terjadi pergeseran $90^{\circ}$. Untuk metode perhitungan daya, berdasarkan pada Orthogonal Signal Generator (OSG) daya aktif P dan daya reaktif $Q$ untuk aplikasi satu fasa dapat dihitung 
dengan bantuan sistem OSG sama seperti pada Persamaan 2 yaitu sebagai berikut[6].

$\mathrm{P}=1 / 2 \quad(\mathrm{v} \alpha . i \alpha+\mathrm{v} \beta . i \beta)$

$\mathrm{Q}=1 / 2(\mathrm{v} \alpha . i \alpha-\mathrm{v} \beta . \mathrm{i} \beta)$

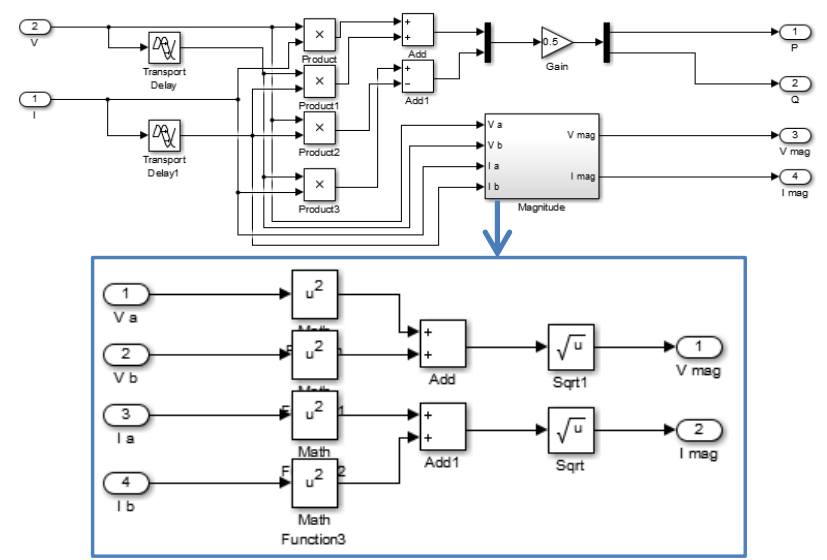

Gambar 5. Simulasi Simulink Monitoring Daya

Dari Gambar 5 dapat diketahui bahwa arus I dan tegangan $\mathrm{V}$ dari inverter digunakan sebagai sinyal masukan pada perhitungan daya untuk sistem monitoring ini. Dimana besar magnitude dan fase dari arus dan tegangan diproses sehingga menghasilkan besaran daya $\mathrm{P}$ dan $\mathrm{Q}$. Untuk mendapatkan daya $\mathrm{P}$, dilakukan dengan cara mengalikan besar magnitude $\mathrm{V}$ dan I kemudian dikalikan dengan fungsi cosinus. Untuk mendapatkan nilai Q, didapatkan dengan cara mengalikan besaran magnitude $\mathrm{V}$ dan I kemudian dikalikan dengan fungsi sinus. Persamaan yang didapat sebagai berikut.

$\mathrm{P}=1 / 2(\mathrm{v} \alpha . \mathrm{i} \alpha+\mathrm{v} \beta . \mathrm{i} \beta)$

$\mathrm{Q}=1 / 2(\mathrm{v} \alpha . \mathrm{i} \alpha-\mathrm{v} \beta . \mathrm{i} \beta)$

Cara memperoleh nilai magnitude dan sudut fase dari Gambar 5 sinyal tegangan dan arus grid inverter ditunda sebesar T/4 periode sehingga diperoleh besaran sinyal $\alpha$ dan $\beta$, dimana sinyal $\alpha$ sinyal awal dan $\beta$ adalah sinyal hasil tundaan $\mathrm{T} / 4$ periode.

\subsection{Perancangan Program}

Program sistem monitoring ini dimulai dengan pembacaan nilai output dari pengkondisi sinyal menggunakan fitur pembacaan nilai ADC, berikut ini adalah program pembacaan ADC:

//baca nilai ADC

const int voltage_sensor $=\mathrm{PA} 0$;

int16_t adc_voltage_value $=0$;

const int current_sensor $=$ PA2;

int16_t adc_current_value $=0$;

Karena memiliki tipe data signed integer, Maka nilai ADC yang masuk akan disimpan menjadi -32767 sampai dengan 32767 (signed integer 16 bit). Selanjutnya adalah membuat nilai $\mathrm{V} \beta$ dan $\mathrm{I} \beta$ dengan menggunakan metode OSG, yaitu dengan cara men-delay $\mathrm{V} \alpha$ dan I $\alpha$ sebanyak 50 sampling. Algoritma OSG dalam program sebagai berikut:

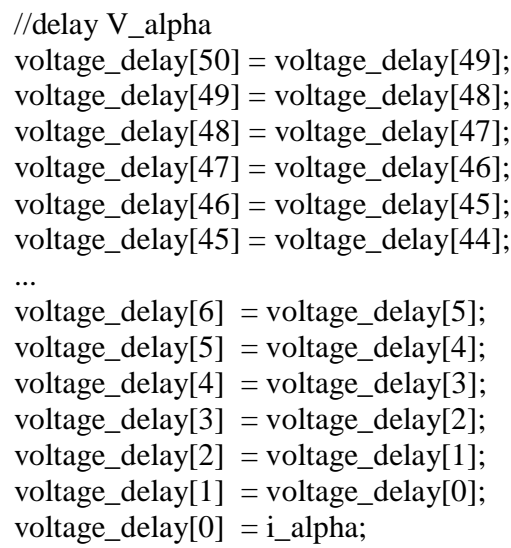

\section{//delay I_alpha}

current_delay[50] = current_delay[49];

current_delay[49] = current_delay[48]; current_delay[48] = current_delay[47]; current_delay[47] = current_delay[46]; current_delay[46] = current_delay[45]; current_delay[45] = current_delay[44];

current_delay $[6]=$ current_delay $[5]$; current_delay[5] = current_delay[4]; current_delay[4] = current_delay[3]; current_delay[3] = current_delay[2]; current_delay[2] = current_delay[1]; current_delay[1] = current_delay[0]; current_delay[0] = v_alpha;

Dikarenakan sistem dianggap seimbang, maka notasi $\mathrm{a}=\alpha$, selanjutnya pembuatan V $\beta$ dan I $\beta$ dengan memanfaatkan interrupt program yang berjalan setiap 0.0001 detik sekali. Karena 1 gelombang AC dari PLN berperiode 0.02 detik, maka dalam 1 periode gelombang input terjadi 200 (0.02 s / $0.0001 \mathrm{~s})$ kali sampling data oleh program. Sehingga program akan ditunda sebanyak 50 kali sampling untuk tundaan $1 / 4$ gelombang $\mathrm{V} \alpha$ dan $\mathrm{I} \alpha$, sehingga didapatkan $\mathrm{V} \beta$ dan $\mathrm{I} \beta$ yang berbeda fase $90^{\circ}$ terhadap V $\alpha$ dan I $\alpha$.

voltage_magnitude $[0]=$

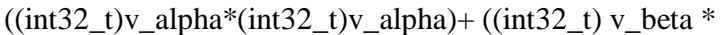

(int32_t)v_beta);

current_magnitude $[0]=$

$(($ int32_t $)$ i_alpha $*($ int32_t $)$ __alpha $)+(($ int 32_t $)$ i_beta $*$

(int32_t)i_beta);

real_power[0]

$\left(((\right.$ int 32_t $)$ v_alpha* $($ int 32_t $)$ __alpha $)+\left((\right.$ int 32_t $) v \_b e t a$

$*($ int32_t $)$ i_beta $))>>1$;

reactive_power[0] $=(($ int32_t $) \mathrm{v}$ _beta $*($ int32_t $)$ __alpha $)$ -

$(($ int32_t $)$ v_alpha $*($ int32_t $)$ i_beta $)>>1$; 
Dari program di atas didapatkan nilai magnitude dari tegangan, arus, daya aktif, daya reaktif. Selanjutnya dilakukan exponential smoothing untuk dilakukan filter sinyal magnitude tersebut agar keluaran yang dihasilkan lebih halus[7].

\section{//smoothing exponential}

voltage_magnitude[2] $=(($ int64_t $) 4290675 *$

(int64_t)voltage_magnitude[0] + (int64_t)2143231972*

(int64_t)voltage_magnitude[1]) $>>31$;

voltage_magnitude[1] = voltage_magnitude[2];

current_magnitude[2] $=((($ int64_t $) 4290675 *($ int64_t $)$

current_magnitude[0] $)+(($ int64_t $) 2143192972 *$

(int64_t)current_magnitude[1])) $>31$;

current_magnitude[1] = current_magnitude[2];

real_power[2] $=((($ int64_t $) 4290675 *($ int64_t $)$ real_power[0] $)$ $+(($ int64_t $) 2143192972 *($ int64_t $)$ real_power[1] $))>>31)$

real_power[1] = real_power[2];

reactive_power[2] $=(($ int64_t $) 4290675 *$ reactive_power[0] $)+$ ((int64_t) 2143192972* reactive_power[1])) >> 31;

reactive_power[1] = reactive_power[2];

Selanjutnya untuk mengirimkan data-data yang telah diproses untuk ditampilkan pada LCD.

\section{//tampil LCD}

lcd.setCursor $(0,0)$;

lcd.print("V=");

lcd.setCursor $(10,0)$;

lcd.print("I=");

lcd.setCursor $(0,1)$;

lcd.print("P=");

lcd.setCursor $(10,1)$;

lcd.print("Q=");

lcd.setCursor( 8,0$)$;

lcd.print("V");

lcd.setCursor(18,0);

lcd.print("A");

lcd.setCursor $(8,1)$;

lcd.print("W");

lcd.setCursor(18,1);

lcd.print("VAR");

delay (500);

\section{Hasil dan Analisis}

Pengujian dilakukan pada hardware dan program yang telah dibuat, dan akan dibandingkan dengan hasil dari pengukuran dari Clamp Meter. Pada bagian hardware, yang pertama akan dilakukan pengujian dan pembahasan mengenai pengkondisi sinyal yang berfungsi menjadikan tegangan masukan AC 1 fasa dari variac $50 \mathrm{~V}$ menjadi sinusoidal 0-3,3V yang dapat dibaca oleh ADC mikrokontroler serta merepresentasikan sinusoidal 1 fase. Yang kedua akan dilakukan running serangkaian program monitoring pada mikrokontroler STM32F103C8T6 yang keluarannya akan ditampilkan pada LCD. Berikut ini
Tabel 1 yang merupakan variable penelitian yang perlu diketahui.

\section{Tabel 1. Variabel Penelitian}

\begin{tabular}{ll}
\hline Variabel & Nilai \\
\hline $\begin{array}{l}\text { Tegangan masukan } \\
\text { pengkondisi sinyal }\end{array}$ & $50-60 \mathrm{~V}$ \\
$\begin{array}{l}\text { Tegangan masukan DC } \\
\text { Keluaran pengkondisi sinyal }\end{array}$ & $12 \mathrm{~V}$ \\
$\begin{array}{l}\text { Tegangan Referensi } \\
\text { mikrokontroler }\end{array}$ & $0-3,3 \mathrm{~V}$ \\
\hline
\end{tabular}

\subsection{Pengujian Rangkaian Pengkondisi Sinyal}

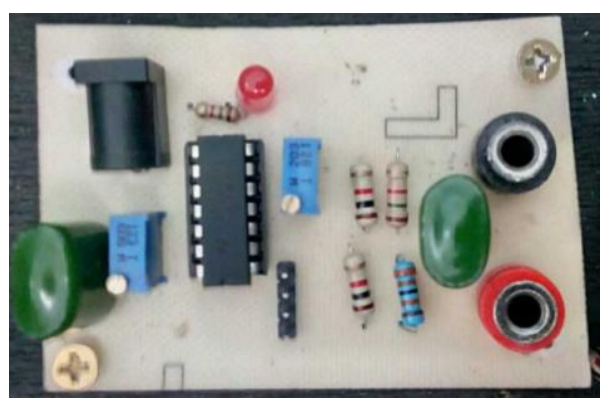

Gambar 6. Hardware Pengkondisi Sinyal

Hardware ini digunakan untuk mengatur gelombang masukan sinusoidal 1 fase dengan cara memutar salah satu atau kedua trimpot sesuai kondisi gelombang yang ada. Gambar 7 merupakan gelombang keluaran pengkondisi sinyal yang telah diatur sedemikian sehingga didapatkan keluaran gelombang seperti pada Gambar 7 berikut.

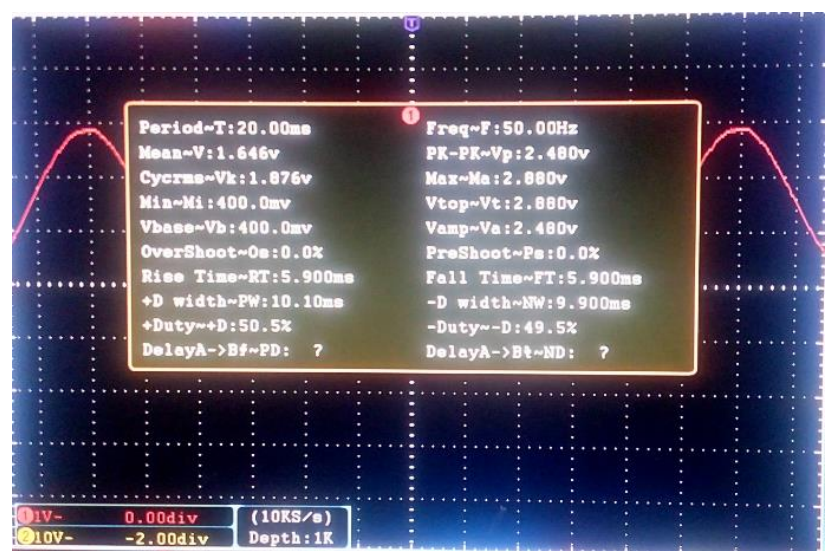

Gambar 7. Gelombang keluaran rangkaian pengkondisi sinyal (1V/div)

Terlihat nilai $\mathrm{Vmin}=400,0 \mathrm{mV}$ dan $\mathrm{V} \max =2,88 \mathrm{~V}$ dengan pengaturan $1 \mathrm{~V} /$ div, artinya garis tengah gelombang tegangan adalah $1,65 \mathrm{~V}$. Hasil gelombang tegangan keluaran pengkondisi sinyal ini sudah sesuai dengan gelombang tegangan pengkondisi sinyal yang diinginkan. 


\subsection{Pengujian Sensor Arus ACS712-05B}

Pengujian Sensor Arus ACS712-05B bertujuan untuk mengetahui apakah keluaran sensor sudah sesuai dengan nilai offset dan sensitivitas pembacaan arus yang sudah diatur sebelumnya. Pengujian dilakukan dengan Oscilloscope OWON pada terminal output (dengan OpAmp) sensor. Pada Gambar 8 menunjukkan rangkaian pengujian output sensor. Pengukuran dilakukan menggunakan satu channel Oscilloscope, dengan probe sinyal yang diilustrasikan dengan kabel merah masuk ke pin output (dengan Op-Amp) dan probe ground yang diilustrasikan dengan kabel biru masuk ke pin ground.

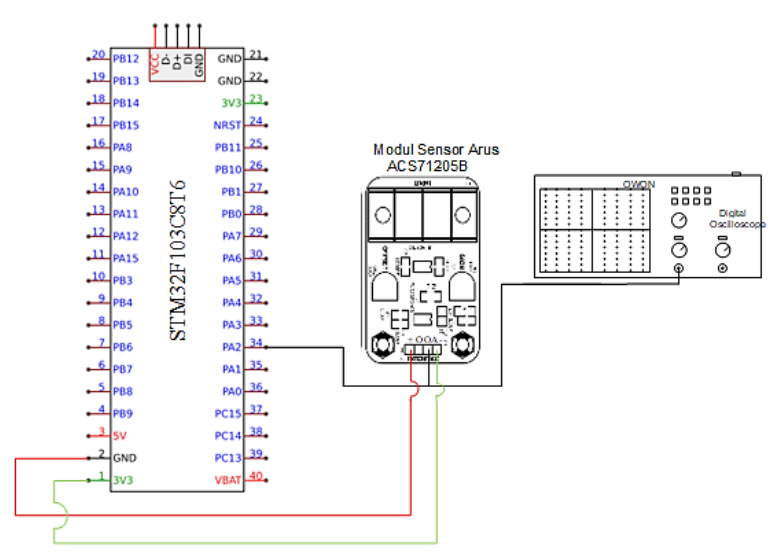

Gambar 8. Rangkaian Pengujian Sensor Arus Tanpa Beban

Pengamatan dilakukan pada $\mathrm{v} / \mathrm{div}=1 \mathrm{~V}, \mathrm{~T} / \mathrm{div}=2 \mathrm{~ms}$ dan faktor pengali probe 1x. Gambar 9 menunjukkan gelombang keluaran sensor arus.

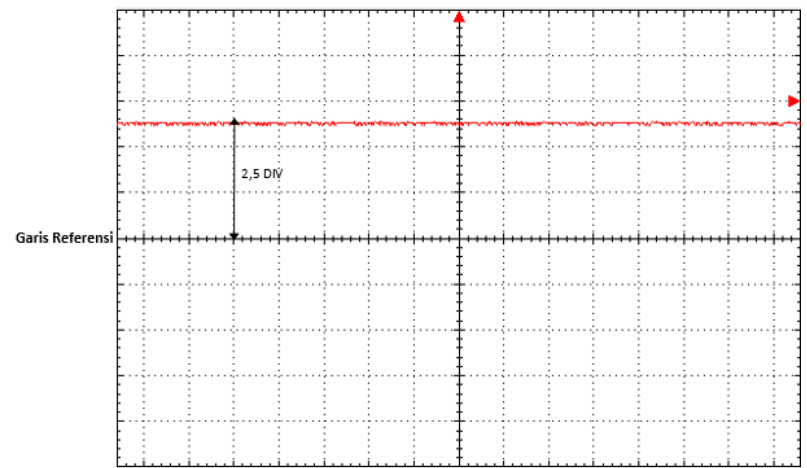

Gambar 9. Gelombang Keluaran Sensor Arus Tanpa Beban

Hasil pengujian sensor pada Gambar 9 diatas sudah sesuai dengan perancangan dimana saat arus $=0 \mathrm{~A}$ maka diperoleh tegangan keluaran sensor melalui Persamaan 4 sebagai berikut.

$V_{\text {out }}=2,5+2,5 . i$

$V_{\text {out }}=2,5+0,5 \cdot 0$

$V_{\text {out }}=2,5 \mathrm{~V}$
Bentuk gelombang output yang ditunjukkan pada Gambar 10 menunjukkan bahwa sinyal keluaran sensor tanpa beban (arus $=0 \mathrm{~A}$ ) adalah $2,5 \mathrm{~V}$ sudah sesuai dengan offset yang ditetapkan. Untuk pengamatan output sensor dengan beban dilakukan pada $\mathrm{v} / \mathrm{div}=1 \mathrm{~V}$, T/div $=5 \mathrm{~ms}$ dan faktor pengali probe 1x. Gambar 10 menunjukkan gelombang keluaran sensor arus.

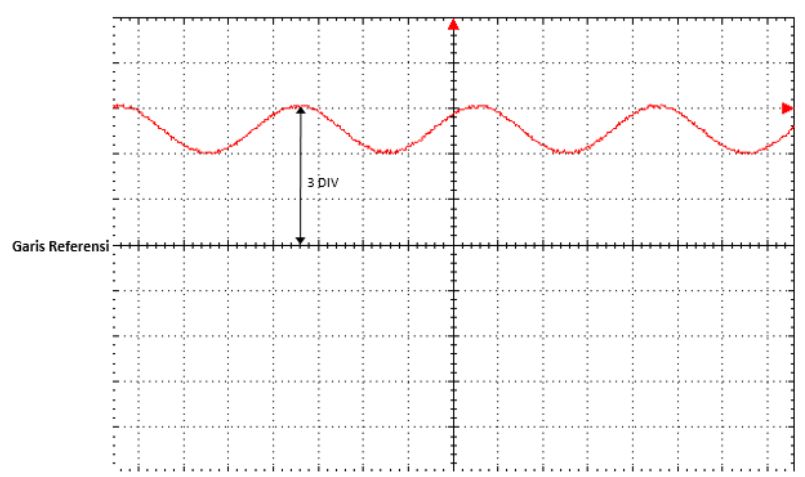

Gambar 10. Gelombang Keluaran Sensor Arus dengan Beban

Berdasarkan Gambar 10 didapatkan gelombang keluaran sensor arus yang memiliki div $=1$ dengan $\mathrm{V} / \mathrm{div}=1$ Volt, sehingga magnitude sinyal yang dihasilkan adalah :

$V_{\text {out }}=2,5+0,5 \cdot i$

$V_{\text {out }}=2,5+0,5 \cdot 1$

$V_{\text {out }}=3 \mathrm{~V}$

Bentuk gelombang output yang ditunjukkan pada Gambar 10 menunjukkan bahwa sinyal keluaran sensor dengan beban $12 \mathrm{ohm}$ (arus = 1A) adalah $3 \mathrm{~V}$ sudah terkalibrasi dengan baik dan siap digunakan.

\subsection{Data Pengukuran Daya 1 Fasa}

\subsubsection{Pengukuran Daya 1 Fasa dengan Beban 9,6 $\Omega$}

Tabel 2. Data Pengukuran Daya 1 Fasa

\begin{tabular}{|c|c|c|c|c|c|c|c|}
\hline \multicolumn{4}{|c|}{ Clampmeter } & \multicolumn{4}{|c|}{ Metode OSG } \\
\hline $\begin{array}{c}\text { Vmag } \\
\text { (V) }\end{array}$ & $\begin{array}{l}\text { Imag } \\
\text { (A) }\end{array}$ & $\begin{array}{c}\text { Daya } \\
\text { Aktif } \\
\text { (W) }\end{array}$ & $\begin{array}{c}\text { Daya } \\
\text { Reaktif } \\
\text { (VAR) }\end{array}$ & $\begin{array}{c}\text { Vmag } \\
\text { (V) }\end{array}$ & $\begin{array}{l}\text { Imag } \\
\text { (A) }\end{array}$ & $\begin{array}{c}\text { Daya } \\
\text { Aktif } \\
\text { (W) }\end{array}$ & $\begin{array}{c}\text { Daya } \\
\text { Reaktif } \\
\text { (VAR) }\end{array}$ \\
\hline 2,9 & 0,22 & 0 & 0 & 2,9 & 0,22 & 0,55 & 0,02 \\
\hline 6,4 & 0,62 & 4 & 0 & 6,4 & 0,63 & 3,88 & 0,09 \\
\hline 9,3 & 0,93 & 9 & 0 & 9,35 & 0,92 & 8,8 & 0,91 \\
\hline 12,8 & 1,31 & 17 & 0 & 12,82 & 1,29 & 16,7 & 0,37 \\
\hline 15,6 & 1,62 & 25 & 0 & 15,51 & 1,62 & 25 & 0,57 \\
\hline 18,3 & 1,89 & 34 & 0 & 18,27 & 1,89 & 34,27 & 1 \\
\hline 22,2 & 2,31 & 52 & 0 & 22 & 2,32 & 51.65 & 1,21 \\
\hline 23,5 & 2,44 & 57 & 0 & 23,51 & 2,44 & 56,92 & 1,27 \\
\hline 26,5 & 2,8 & 74 & 0 & 26,71 & 2,77 & 73,6 & 1,7 \\
\hline 29 & 3,08 & 89 & 0 & 28,86 & 3,05 & 88,44 & 1,8 \\
\hline
\end{tabular}

Dari Tabel 2 dan Tabel 3 didapatkan hasil pengukuran tegangan didapatkan nilai rata-rata error $0,32 \%$ pada beban 9,6 Ohm sehingga dapat dikategorikan sebagai alat ukur presisi[5]. Untuk pengukuran arus, didapatkan didapatkan nilai rata-rata error $0,67 \%$, sehingga dikategorikan sebagai alat ukur kerja. Untuk pengukuran 
daya aktif, didapatkan didapatkan nilai rata-rata error $1 \%$, sehingga dikategorikan sebagai alat ukur kerja. Untuk pengukuran daya reaktif, didapatkan nilai rata-rata selisih 0,89 VAR sehingga nilai ini sudah presisi karena memiliki selisih nilai yang kecil.

Tabel 3. Error Pengujian

\begin{tabular}{|c|c|c|c|}
\hline \multicolumn{3}{|c|}{ Error } & \multirow[b]{2}{*}{$\begin{array}{c}\text { Selisih } \\
\text { Daya } \\
\text { Reakti }\end{array}$} \\
\hline $\begin{array}{c}\text { Tegangan } \\
\text { (V) }\end{array}$ & $\begin{array}{l}\text { Arus } \\
\text { (A) }\end{array}$ & $\begin{array}{c}\text { Daya } \\
\text { Aktif } \\
\text { (W) }\end{array}$ & \\
\hline $0 \%$ & 8 & - & 0,02 \\
\hline $0 \%$ & $2 \%$ & $3 \%$ & 0,09 \\
\hline $1 \%$ & $1 \%$ & $2 \%$ & 0,91 \\
\hline $0 \%$ & $2 \%$ & $2 \%$ & 0,37 \\
\hline $1 \%$ & $0 \%$ & $0 \%$ & 0,57 \\
\hline $0 \%$ & $0 \%$ & $1 \%$ & 1 \\
\hline $1 \%$ & $0 \%$ & $0 \%$ & 1,21 \\
\hline $0 \%$ & $0 \%$ & $0 \%$ & 1,27 \\
\hline $1 \%$ & $1 \%$ & $1 \%$ & 1,7 \\
\hline $0 \%$ & $1 \%$ & $1 \%$ & 1,8 \\
\hline
\end{tabular}

3.3.2. Pengukuran Daya 1 Fasa dengan Beban $47,5 \Omega$

Tabel 4. Daya Pengukuran 1 Fasa

\begin{tabular}{|c|c|c|c|c|c|c|c|}
\hline \multicolumn{4}{|c|}{ Clampmeter } & \multicolumn{4}{|c|}{ LCD } \\
\hline $\begin{array}{c}\text { Vmag } \\
\text { (V) }\end{array}$ & $\begin{array}{l}\text { Imag } \\
\text { (A) }\end{array}$ & $\begin{array}{c}\text { Daya } \\
\text { Aktif } \\
\text { (W) }\end{array}$ & $\begin{array}{c}\text { Daya } \\
\text { Reaktif } \\
\text { (VAR) }\end{array}$ & $\begin{array}{c}\text { Vmag } \\
\text { (V) }\end{array}$ & $\begin{array}{l}\text { Imag } \\
\text { (A) }\end{array}$ & $\begin{array}{c}\text { Daya } \\
\text { Aktif } \\
\text { (W) }\end{array}$ & $\begin{array}{c}\text { Daya } \\
\text { Reaktif } \\
\text { (VAR) }\end{array}$ \\
\hline 4,1 & 0 & 0 & 0 & 4,19 & 0,01 & 0,024 & 0,01 \\
\hline 8,3 & 0 & 0 & 0 & 8,37 & 0,03 & 0,334 & 0,05 \\
\hline 11,6 & 0 & 0 & 0 & 11,59 & 0,05 & 0,664 & 0,01 \\
\hline 16,3 & 0,34 & 6 & 0 & 16,34 & 0,35 & 5,8 & 0,113 \\
\hline 20 & 0,42 & 8 & 0 & 20,2 & 0,42 & 8,2 & 0,2 \\
\hline 24,4 & 0,51 & 13 & 0 & 24 & 0,52 & 12,8 & 0,29 \\
\hline 27,9 & 0,59 & 16 & 0 & 27,93 & 0,59 & 16,33 & 0,39 \\
\hline 33 & 0,7 & 23 & 0 & 33,01 & 0,7 & 23 & 0,54 \\
\hline 36,1 & 0,76 & 28 & 0 & 36,22 & 0,76 & 27,73 & 0,61 \\
\hline 41,1 & 0,86 & 35 & 0 & 41,12 & 0,87 & 35,38 & 0,83 \\
\hline
\end{tabular}

Tabel 5. Error Pengujian

\begin{tabular}{|c|c|c|c|}
\hline \multicolumn{3}{|c|}{ Error } & \multirow[b]{2}{*}{$\begin{array}{c}\text { Selisih } \\
\text { Daya } \\
\text { Reakti }\end{array}$} \\
\hline $\begin{array}{c}\text { Tegangan } \\
\text { (V) }\end{array}$ & $\begin{array}{l}\text { Arus } \\
\text { (A) }\end{array}$ & $\begin{array}{c}\text { Daya } \\
\text { Aktif } \\
\text { (W) }\end{array}$ & \\
\hline $2 \%$ & - & - & 0,01 \\
\hline $1 \%$ & - & - & 0,05 \\
\hline $0 \%$ & - & - & 0,01 \\
\hline $0 \%$ & $3 \%$ & $3 \%$ & 0,113 \\
\hline $1 \%$ & $0 \%$ & $2 \%$ & 0,2 \\
\hline $2 \%$ & $2 \%$ & $2 \%$ & 0,29 \\
\hline $0 \%$ & $0 \%$ & $2 \%$ & 0,39 \\
\hline $0 \%$ & $0 \%$ & $0 \%$ & 0,54 \\
\hline $0 \%$ & $0 \%$ & $1 \%$ & 0,61 \\
\hline $0 \%$ & $1 \%$ & $1 \%$ & 0,83 \\
\hline
\end{tabular}

Dari Tabel 4 dan Tabel 5 didapatkan hasil pengukuran tegangan didapatkan nilai rata-rata error $0,65 \%$ pada beban 9,6 Ohm sehingga dapat dikategorikan sebagai alat ukur kerja[5]. Untuk pengukuran arus, didapatkan didapatkan nilai rata-rata error $0,87 \%$, sehingga dikategorikan sebagai alat ukur kerja. Untuk pengukuran daya aktif, didapatkan didapatkan nilai rata-rata error
1,64\%, sehingga dikategorikan sebagai alat ukur kerja. Untuk pengukuran daya reaktif, didapatkan nilai rata-rata selisih 0,83 VAR sehingga nilai ini sudah presisi karena memiliki selisih nilai yang kecil.

\section{Kesimpulan}

Berdasarkan perancangan, pengujian dan analisa yang telah dilakukan maka dapat dibuat kesimpulan sistem monitoring daya satu fasa telah berhasil direalisasikan menggunakan mikrokontroler STM32F103C8T6 dan dapat menghasilkan data tegangan, arus, daya aktif dan daya reaktif. Nilai rata-rata error magnitude tegangan pada beban $9,6 \mathrm{ohm}$ dan $47,5 \mathrm{ohm}$ sebesar $0,32 \%$ dan $0,65 \%$, menurut buku PLN[8] alat termasuk dalam alat cermat pada nilai rata-rata error $0,32 \%$ dan alat kerja pada rata-rata error $0,65 \%$. Untuk magnitude arus diperoleh rata-rata error sebesar $0,67 \%$ dan $0,87 \%$ sehingga termasuk alat kerja. Untuk nilai daya aktif diperoleh rata-rata error $1 \%$ dan $1,64 \%$ sehingga termasuk alat kerja. Untuk daya reaktif diperoleh selisih sebesar 0,89 VAR dan 0,83 VAR. Secara keseluruhan, alat ini masih dalam ranah alat kerja mengingat error berkisar $0,32 \%-1,64 \%$.

\section{Referensi}

[1] Xue, Yaosuo, "Topologies of Single Phase Inverters for Small Distributed Power Generators: An Overview," IEEE Transactions on Power Electronics, vol.19, pp.1305-1314, 2004.

[2] Daniel W.Hart, Power Electronics. 2011.

[3] PT PLN (Persero), Pedoman Penyambungan Pembangkit Listrik Energi Terbarukan Ke Sistem Distribusi PLN, 22 Juli 2014.

[4] Y. Yoheng and Frede Blaabjerg, "A New Power Calculation Method for Single-Phase GridConnected Systems", ISIE, 2013.

[5] E. H. Watanabe, S. Member, J. L. Afonso, J. G. Pinto, and S. Member, "Instantaneous p-q Power Theory for Control of Compensators in Micro-Grids," 2010.

[6] Y. Yoheng and Frede Blaabjerg, "A New Power Calculation Method for Single-Phase GridConnected Systems", ISIE, 2013.

[7] Yeffry Handoko Putra, John Adler, Gugun Gunawan, “Aplikasi Filter Finite Impulse Response (FIR) Untuk Menghilangkan Noise Pada Suara Manusia Menggunakan Graphical User Interface (GUI) Pemrograman Matlab”, Jurnal Unikom Bandung,

[8] Pusat Pendidikan dan Pelatihan, Instrumentasi Dan Pengukuran Listrik, PT PLN (Persero) 